\title{
Rain-Rate Estimation in the Presence of Hail Using S-Band Specific Differential Phase and Other Radar Parameters
}

\author{
K. AYDIN \\ Department of Electrical Engineering, The Pennsylvania State University, University Park, Pennsylvania \\ V. N. BRINGI AND L. LIU \\ Department of Electrical Engineering, Colorado State University, Fort Collins, Colorado
}

(Manuscript received 21 February 1994, in final form 23 June 1994)

ABSTRACT

\begin{abstract}
Multiparameter radar measurements were made during a heavy rainfall event accompanied by hail in Colorado. Rainfall rates $R$ and accumulation $\Sigma$ for this event were estimated using $S$-band specific differential phase $K_{\mathrm{DP}}$, reflectivity factor $Z_{H}$, and $\mathrm{X}$-band specific attenuation $A_{H 3}$. These estimates were compared with measurements from a ground-based rain gauge. Both $R-K_{\mathrm{DP}}$ and $R-A_{H 3}$ relations were in good agreement with the rain gauge data, that is, less than $10 \%$ difference in the rainfall accumulations. The $R-Z$ relation produced similar results only when $Z_{H}$ was truncated at $55 \mathrm{dBZ}$. This study demonstrates the potential of $K_{\mathrm{DP}}$ for estimating rainfall rates in severe storms that may have rain-hail mixtures.
\end{abstract}

\section{Introduction}

An important problem in radar meteorology is the estimation of rainfall rate $R$ in heavy precipitation that can lead to flash floods. When such precipitation is composed of a mixture of rain and hail, $R-Z_{H}$ and $R-$ $\left(Z_{H}, Z_{\mathrm{DR}}\right)$ relations (Battan 1973; Seliga and Bringi 1976 ) can lead to significant errors. In the case of $R-$ $Z_{H}$, since $Z_{H}$ is proportional to the sixth moment of particle size in the Rayleigh regime, it is significantly affected by hailstones that are larger in size than most raindrops. On the other hand, the $R-\left(Z_{H}, Z_{\mathrm{DR}}\right)$ relation is affected by this bias in $Z_{H}$ as well as bias in $Z_{\mathrm{DR}}$ toward the larger hailstones. Since $Z_{\mathrm{DR}}$ is the reflectivity-weighted mean axial ratio (Jameson 1983) and hailstones have mean axial ratios much closer to 1 (as compared to large raindrops), its value is significantly reduced by the presence of hailstones. In fact these aspects of $Z_{H}$ and $Z_{\mathrm{DR}}$ are used for detecting hail (Bringi et al. 1984; Aydin et al. 1986).

This paper presents a case study of S-band (10.9$\mathrm{cm}$ wavelength) radar rainfall estimation in the presence of hail using one-way specific differential phase $K_{\mathrm{DP}}$ between $H$ and $V$ polarizations compared with a ground-based rain gauge. One-way specific attenuation $A_{H 3}$ at $\mathrm{X}$ band (3.2-cm wavelength) is used as another

Corresponding author address: Prof. Kultegin Aydin, Department of Electrical Engineering, The Pennsylvania State University, University Park, PA 16802. estimator of $R$ for comparison with the rain gauge in the same rainfall event. Both $K_{\mathrm{DP}}$ and $A_{H 3}$ are forwardscattering parameters as opposed to $Z_{H}$ and $Z_{\mathrm{DR}}$, which are backscattering parameters. The specific differential phase $K_{\mathrm{DP}}$ is not affected very much by the presence of hailstones that have mean axial ratios close to 1 and/or are tumbling (Balakrishnan and Zrnić 1990). It is dominated by oriented oblate spheroidal raindrops. Therefore, it is a valuable parameter for estimating $R$ in a rain-hail mixture. On the other hand, $A_{H 3}$ is proportional to about the third moment of particle size for sizes in the range 3.9-6 mm (Jameson 1991) and therefore is not as significantly affected by hailstones mixed with raindrops as $Z_{H}$ is at $\mathrm{S}$ band. The main drawback of $A_{H 3}$ is that two radars are needed to measure it.

\section{Rainfall rate-radar parameter relations}

Specific differential phase has been considered for estimating rainfall rate (Seliga and Bringi 1978; Doviak and Zrnić 1993) and various estimators have been proposed (Jameson and Mueller 1985; Sachidananda and Zrnić 1986). Several S-band $R-K_{\mathrm{DP}}$ relations exist in the literature. Among these are $R=37.1 K_{\mathrm{DP}}^{0.866}$ (Sachidananda and Zrnić 1987), and $R=36.15 K_{\mathrm{DP}}^{0.84}$ for $0.01^{\circ}<K_{\mathrm{DP}}<1.5^{\circ} \mathrm{km}^{-1}$ and $33.77 K_{\mathrm{DP}}^{0.97}$, for $1.5^{\circ}$ $\leqslant K_{\mathrm{DP}}<7^{\circ} \mathrm{km}^{-1}$ (Aydin and Giridhar 1992), which are termed the $S Z$ and $A G$ relationships, respectively. Here we use the relationship (Chandrasekar et al. 1990)

$$
R_{\mathrm{KDP}}=40.5 K_{\mathrm{DP}}^{0.85}\left(\mathrm{~mm} \mathrm{~h}^{-1}\right) \text {, }
$$


where $K_{\mathrm{DP}}$ has units of degrees per kilometer. The parameters $a$ and $b$ of the relation $R_{\mathrm{KDP}}=a K_{\mathrm{DP}}^{b}$ are obtained by a nonlinear regression technique. The AG relationship is based on disdrometer measurements of raindrop size distributions. Equation (1) is derived from a gamma drop size distribution by varying the gamma parameters $\left(N_{0}, m, D_{0}\right)$ over a wide range (Ulbrich 1983). The SZ relation is based on the Marshall-Palmer (1948) drop size distribution with $N_{0}=8000 \mathrm{~m}^{-3} \mathrm{~mm}^{-1}$. Because (1) incorporates a more general gamma distribution it is used in this paper. The differences between (1) and the SZ and AG relations are less than $6 \%$ for $100 \leqslant R<200 \mathrm{~mm} \mathrm{~h}^{-1}$ and less than $12 \%$ for $R<100 \mathrm{~mm} \mathrm{~h}^{-1}$. Note that (1) produces larger rain rates than both the $S Z$ and $A G$ relations when $R<147 \mathrm{~mm} \mathrm{~h}^{-1}$.

The use of specific attenuation at $\mathrm{X}$ band $\left(A_{H 3}\right)$ on a microwave link for estimating rainfall has also been considered (Atlas and Ulbrich 1977). In this study the temperature-averaged relation given by Jameson (1992) is used:

$$
R_{A H 3}=54.6 A_{H 3}^{0.845} \quad\left(\mathrm{~mm} \mathrm{~h}^{-1}\right),
$$

where $A_{H 3}$ is in decibels per kilometer.

The next section describes how $K_{\mathrm{DP}}$ and $A_{H 3}$ are estimated. Both estimators are insensitive to the $a b-$ solute gain of the radars (Doviak and Zrnic 1993).

A $Z-R$ relation adopted for WSR-88D (NEXRADNext Generation Weather Radar) operations will also be used to compare its performance. This relation is (Kelsh 1989)

$$
R_{Z}=0.017 Z^{0.714}\left(\mathrm{~mm} \mathrm{~h}^{-1}\right),
$$

where $Z$ is in its standard units $\left(\mathrm{mm}^{6} \mathrm{~m}^{-3}\right)$. This $Z$ $R$ relation is truncated at an operator-specified maximum reflectivity value, depending on the geographical region for which it is used.

\section{Heavy rainfall event}

On 24 June 1992 a severe storm left nearly $75 \mathrm{~mm}$ (3") of rain between 1515 and 1615 MDT in Fort Collins, Colorado. Observers at the main campus of Colorado State University (CSU) noted that precipitation started with a few big drops followed by intense rain and then mixed with hailstones of $15-20 \mathrm{~mm}$ in diameter. The storm system moved in the east-southeast direction and was scanned by the CSU-CHILL and NCAR's CP-2 and Mile High radars. An overview of this storm was previously given by Bringi et al. (1993).

Figure 1 is a constant-altitude ( $1.5 \mathrm{~km} \mathrm{AGL)} \mathrm{PPI}$ (plan position indicator) section from the CSU-CHILL radar at $1536 \mathrm{MDT}$, showing reflectivity factor $Z_{H}$, with $Z_{\mathrm{DR}}$ and $K_{\mathrm{DP}}$ fields. The peak reflectivity is 63.2 $\mathrm{dBZ}$ at $x=-37 \mathrm{~km}, y=16 \mathrm{~km}$, the radar location being at $(0,0)$. The $Z_{\mathrm{DR}}$ hail signature indicates a hail core at about $(-39,16) \mathrm{km}$, where $Z_{\mathrm{DR}}<0.5 \mathrm{~dB}$ and $Z_{H}>60 \mathrm{dBZ}$. In fact the entire region with $Z_{H}>45$ $\mathrm{dBZ}$ and $Z_{\mathrm{DR}}<0.5 \mathrm{~dB}$ likely contains hail (Aydin et al. 1986). The rain gauge is located at $(-37.7,15.3)$ $\mathrm{km}$, that is, $292.2^{\circ}$ azimuth and $40.7-\mathrm{km}$ radial distance from CHILL, and is at the border of the region containing hail.

Figure 1 also shows several regions of high $K_{\mathrm{DP}}$ within the $Z_{H}>50 \mathrm{dBZ}$ contour, one of which is in the hail region described above, the peak $K_{\mathrm{DP}}$ being $3.6^{\circ} \mathrm{km}^{-1}$ at $(-38,16) \mathrm{km}$. The high values of $K_{\mathrm{DP}}$ suggest that rainfall is dominant in this region even though it may contain hail.

Figure 2 shows S-band CSU-CHILL radar measurements of $Z_{H}, K_{\mathrm{DP}}, \phi_{\mathrm{DP}}$ (two-way propagation differential phase shift ), $Z_{\mathrm{DR}}$, and $R_{\mathrm{KDP}}$ along a ray. The $Z_{H}, Z_{\mathrm{DR}}$, and $\phi_{\mathrm{DP}}$ data corresponding to $150-\mathrm{m}$ range gates are passed through an infinite impulse response filter (termed "light" filter in Fig. 2) that attenuates spatial fluctuations less than $300 \mathrm{~m}$ by more than $15 \mathrm{~dB}$. This "lightly" filtered $\phi_{\mathrm{DP}}$ is adaptively filtered using a finite impulse response filter (termed "adaptive" filter in Fig. 2) that attenuates spatial fluctuations less than $1.5 \mathrm{~km}$ by more than $15 \mathrm{~dB}$ (Hubbert et al. 1993). Differential phase $K_{\mathrm{DP}}$ is then calculated as onehalf the slope of the adaptively filtered $\phi_{\mathrm{DP}}, K_{\mathrm{DP}}$ $=\left[\phi_{\mathrm{DP}}\left(r_{2}\right)-\phi_{\mathrm{DP}}\left(r_{1}\right)\right] /\left[2\left(r_{2}-r_{1}\right)\right]$, where $2\left(r_{2}-r_{1}\right)$ $=300 \mathrm{~m}$. The resulting $K_{\mathrm{DP}}$ accuracy is estimated to be within $\pm 0.5^{\circ} \mathrm{km}^{-1}$. This error estimate is based on analysis of statistical fluctuations of radar data in light rain at vertical incidence where mean $K_{\mathrm{DP}}$ should be zero (Liu et al. 1993). We note that Liu et al. (1993) estimated the accuracy of mean $K_{\mathrm{DP}}$ as $\pm 0.25^{\circ} \mathrm{km}^{-1}$ in conditions of very high $\rho_{h v}(>0.985)$ and using 128 sample $H-V$ pairs in the estimate of $\phi_{\mathrm{DP}}$ at any one resolution volume. We have degraded this accuracy here by a factor of 2 to account for lowered $\rho_{h v}$ found in convective storms (Liu et al. 1995), and the reduced number of sample $H-V$ pairs (64) used when these 24 June data were collected. Note the high values of $K_{\mathrm{DP}}$ in the two cores at about 21 and $42 \mathrm{~km}$, exceeding $6^{\circ} \mathrm{km}^{-1}$ in the latter. In the core at $42 \mathrm{~km}, Z_{\mathrm{DR}}$ is very low and fluctuates about $0 \mathrm{~dB}$, whereas $Z_{H}$ is very high and exceeds $55 \mathrm{dBZ}$, indicating the presence of hailstones. The rainfall rate $R_{\mathrm{KDP}}$ estimated from $K_{\mathrm{DP}}$ is above $190 \mathrm{~mm} \mathrm{~h}^{-1}$ in this core.

Figure 3 shows CP-2 radar measurements of $Z_{H}(\mathrm{~S}$ band), $Z_{H 3}$ (X band), $Z_{\mathrm{DR}}$ ( $\mathrm{S}$ band), dual-frequency ratio $\mathrm{DFR} \equiv Z_{H}-Z_{H 3}(\mathrm{~dB})$, and $R_{A H 3}$ along a ray. The rain gauge is located at $8.2^{\circ}$ azimuth and 71.4$\mathrm{km}$ radial distance from the CP-2 radar. The processing of the reflectivity factors and differential reflectivity are the same as described for the CHILL radar measurements. The processing of DFR is identical to that of $\phi_{\mathrm{DP}}$. The specific attenuation $A_{H 3}$ is calculated as onehalf the slope of the adaptively filtered DFR just as $K_{\mathrm{DP}}$ is obtained from $\phi_{\mathrm{DP}}$. The accuracy in $A_{H 3}$ is es- 

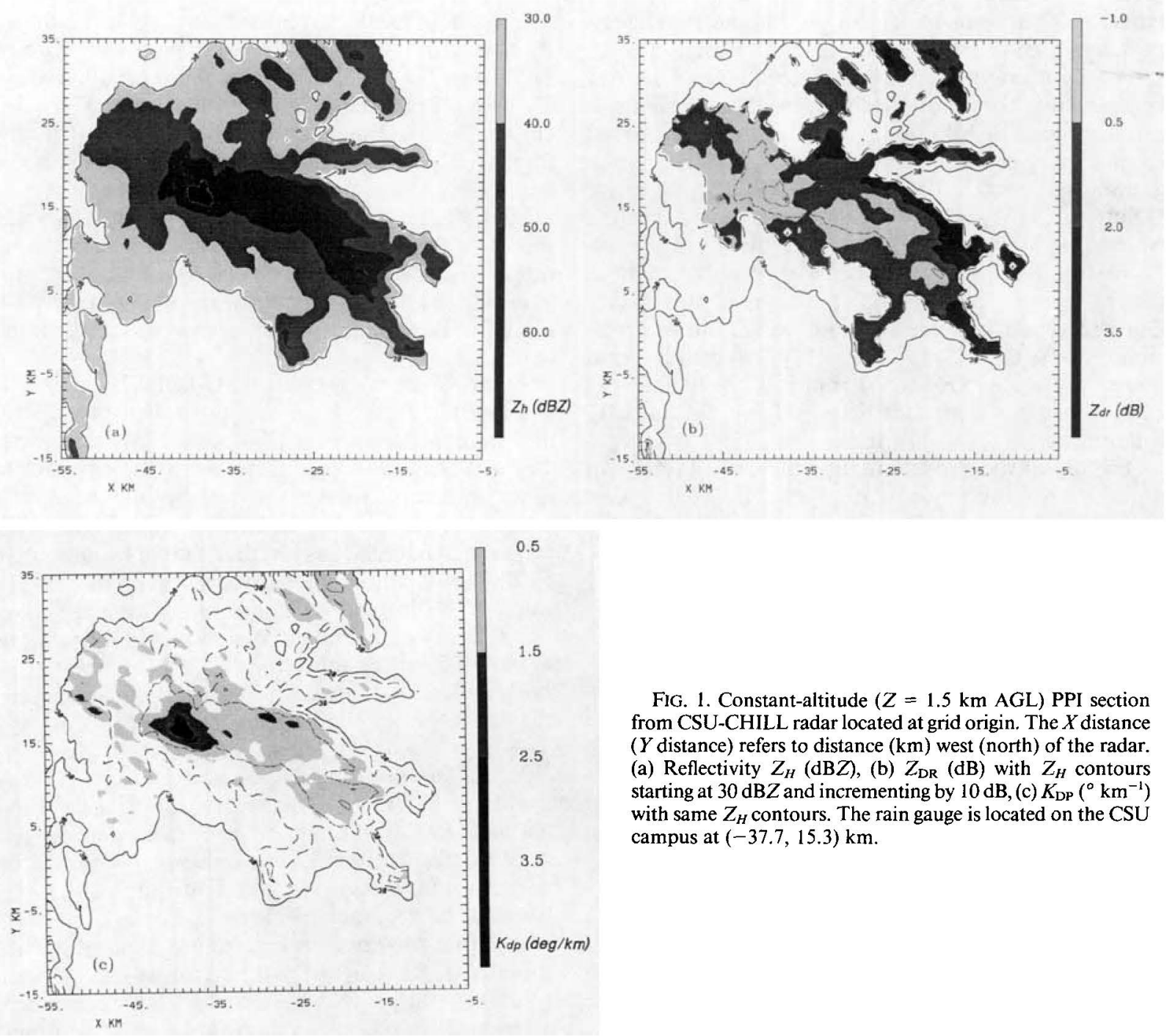

FIG. 1. Constant-altitude ( $Z=1.5 \mathrm{~km}$ AGL) PPI section from CSU-CHILL radar located at grid origin. The $X$ distance ( $Y$ distance) refers to distance $(\mathrm{km})$ west (north) of the radar. (a) Reflectivity $Z_{H}(\mathrm{~dB} Z)$, (b) $Z_{\mathrm{DR}}(\mathrm{dB})$ with $Z_{H}$ contours starting at $30 \mathrm{~dB} Z$ and incrementing by $10 \mathrm{~dB}$, (c) $K_{\mathrm{DP}}\left({ }^{\circ} \mathrm{km}^{-1}\right)$ with same $Z_{H}$ contours. The rain gauge is located on the CSU campus at $(-37.7,15.3) \mathrm{km}$.

timated to be $\pm 0.5 \mathrm{~dB} \mathrm{~km}^{-1}$, which again (has been degraded by a factor of 2 ) is based on an analysis of statistical fluctuations of DFR data in light rain at vertical incidence where mean $A_{H 3}$ should be zero (Liu et al. 1993). Note the intense attenuation at $X$ band as seen in the dramatic reduction of $Z_{H 3}$ relative to $Z_{H}$ as the beam penetrates the core at about $71 \mathrm{~km}$. The rainfall rate $R_{A H 3}$ estimated from $A_{H 3}$ exceeds 200 $\mathrm{mm} \mathrm{h}^{-1}$ in this core. Differential reflectivity $Z_{\mathrm{DR}}$ in the core is less than $0.5 \mathrm{~dB}$ whereas $Z_{H}$ exceeds $65 \mathrm{dBZ}$, indicating the presence of hail. The rain gauge is about $2.5 \mathrm{~km}$ east of this ray at $71.4-\mathrm{km}$ range. Note that this is the same core seen in Fig. 2 by the CHILL radar at $42 \mathrm{~km}$, but at a slightly earlier time. Also note that beyond $74-\mathrm{km}$ range the $\mathrm{X}$-band signal falls below noise level.

\section{Radar-rain gauge comparison of rainfall}

The rain gauge used in this study was operated by the Colorado Climate Center and was located at the
Colorado State University main campus weather station. It was a $30.5-\mathrm{cm}\left(12^{\prime \prime}\right)$ dual transverse universal weighing-bucket gauge with an analog chart recorder. The rainfall rates estimated from the graphical recording were obtained from 5 -min accumulations. It is possible to make $\pm 15 \%$ error in $R$ due to errors reading the graph resulting from heavy rainfall and hail. However, the error in reading the total accumulation is very low, less than about $1 \mathrm{~mm}$. These errors are separate from the measurement errors of the rain gauge itself. For example, the rain gauge can experience reduced catch during wind-driven precipitation as was probably the case during the 24 June storm. Based on experience with gauges of this type, the errors due to the wind-driven rain and random sampling are likely to be approximately $15 \%-20 \%$ (N. Doesken 1994, personal communication). In this case the official standard manual rain gauge, from which historic records are derived, indicated $14 \%$ less rainfall accumulation compared to the recording 


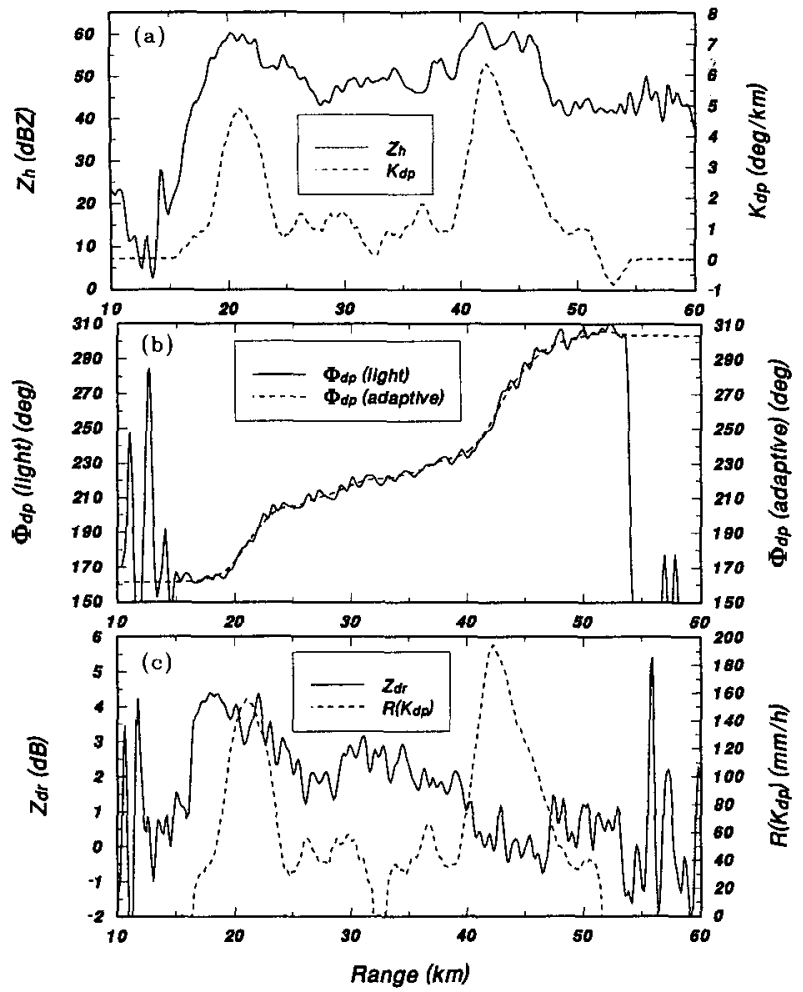

FIG. 2. Range profiles of (a) $Z_{H}$ and $K_{\mathrm{DP}}$, (b) $\phi_{\mathrm{DP}}$ (both lightly and adaptively filtered versions), and (c) $Z_{\mathrm{DR}}$ and $R_{\mathrm{KDP}}$, from a CHILL radar ray through the storm system shown in Fig. 1, at time 1538:38 MDT 24 June 1992, and with elevation and azimuth angles being $0.9^{\circ}$ and $292.2^{\circ}$, respectively.

weighing-bucket gauge that was located $3 \mathrm{~m}$ away ( $\mathrm{N}$. Doesken 1994, personal communication ).

Two methods were used to compare the radar estimates of $R$ with those measured by the rain gauge. Method 1 involved taking into account the horizontal transport of raindrops due to rain cell motion and integrating $R$ along the cell path. Method 2 considered only the range gate directly above the rain gauge. A detailed description of these methods and the resulting rain gauge comparisons are given below.

\section{a. Method 1}

The track of the cell that passed over the rain gauge was determined by observing the location of the $K_{\mathrm{DP}}$ core at different times during the rainfall event. This analysis showed that the cell moved in a direction about $70^{\circ}$ from the north at a speed of $4 \mathrm{~m} \mathrm{~s}^{-1}$. It should be noted that the results presented here were negligibly affected when the cell track direction was taken as $60^{\circ}$ or $80^{\circ}$ from the north. Similarly, small changes $( \pm 0.5$ $\mathrm{m} \mathrm{s}^{-1}$ ) in the velocity of the cell had negligible effects on the results. The lowest elevation angle PPI scans $\left(0.8^{\circ}\right.$ for CHILL and $0.5^{\circ}$ for $\mathrm{CP}-2$, both corresponding to beam centers $600 \mathrm{~m}$ above ground at the rain gauge location) were used to estimate rainfall rate. Eight of the lowest elevation angle scans were available from each radar at approximate intervals of $4 \mathrm{~min}$ for CSUCHILL and $6 \mathrm{~min}$ for CP-2. This provided observations of the rain as close as possible to the ground, reducing errors due to advection. Along the cell track a $1200-\mathrm{m}$ section was selected for estimating $R$. This corresponds to a 5-min travel distance of the cell that matches the time resolution of the rain gauge data. When projected on the ground, the leading edge of this $1200-\mathrm{m}$ swath along the cell track was selected to be $200 \mathrm{~m}$ from the rain gauge. This allowed time, about $50 \mathrm{~s}$ at $4 \mathrm{~m} \mathrm{~s}^{-1}$ cell speed, for the largest precipitation particles from the leading edge of the swath to reach the ground at the rain gauge site. Changing the location of the leading edge to be 100 or $300 \mathrm{~m}$ from the rain gauge resulted in minor fluctuations (within $\pm 5 \%$ for CHILL and $\pm 2 \%$ for CP- 2 ) in the estimates of $R$. The data obtained from each of the lowest elevation angle PPI scans in this manner were placed at a time $200 \mathrm{~s}$ later than the time of the PPI scan. The $200 \mathrm{~s}$ corresponds to the time the center of the $1200-\mathrm{m}$ swath reaches the rain gauge location.

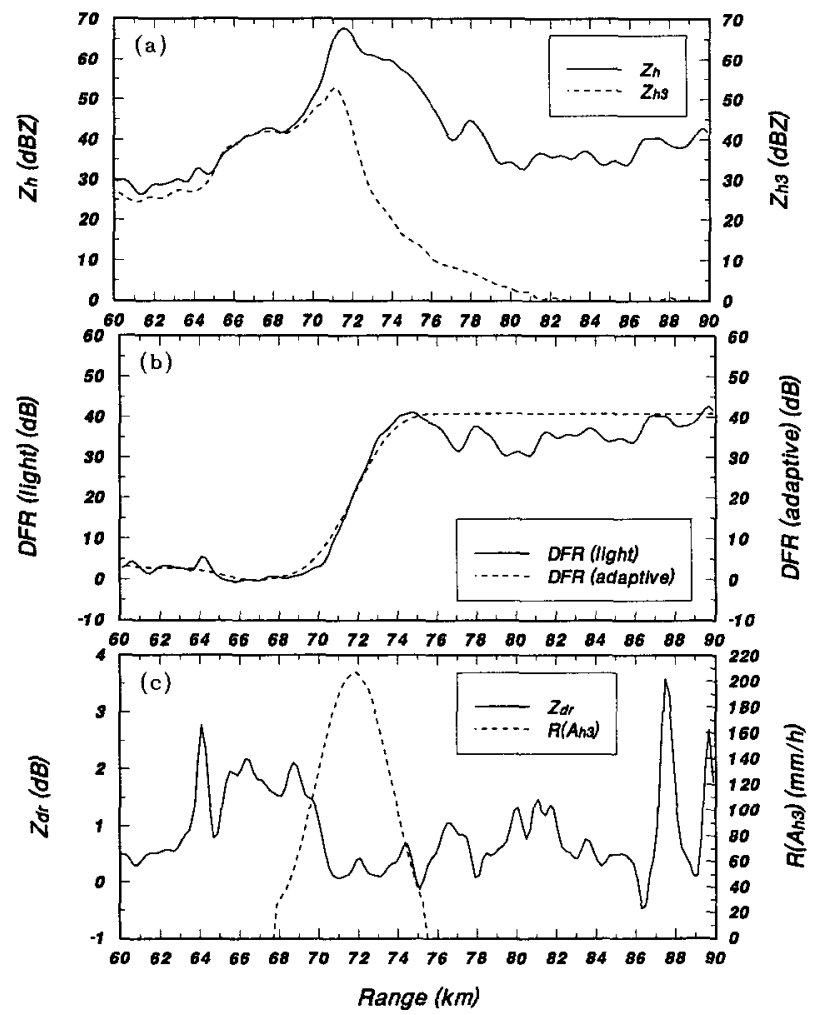

FIG. 3. Range profiles of (a) $Z_{H}$ (S band) and $Z_{H 3}$ (X band), (b) DFR (both lightly and adaptively filtered versions), and (c) $Z_{D R}$ and $R_{A H 3}$, from a CP-2 radar ray through the storm system shown in Fig. 1, at time 1535:54 MDT 24 June 1992, and with elevation and azimuth angles being $0.6^{\circ}$ and $6.2^{\circ}$, respectively. 

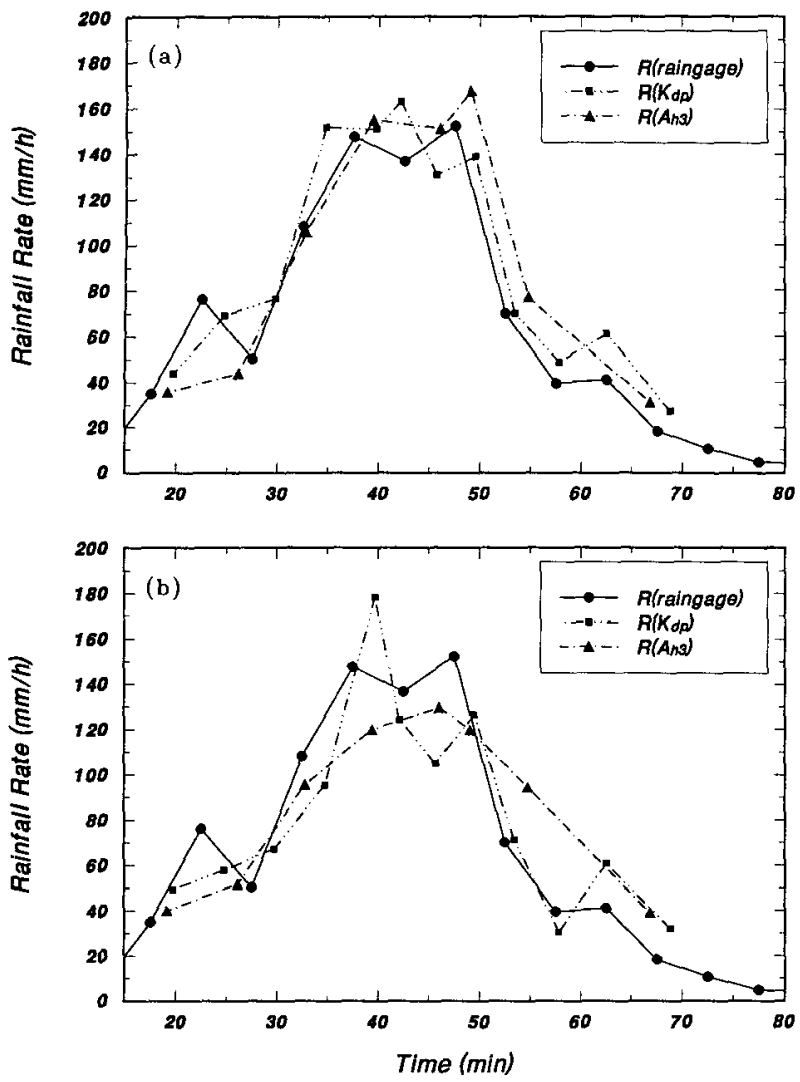

FIG. 4. Rainfall rates measured by the rain gauge and estimated from radar measurements of $K_{\mathrm{DP}}$ and $A_{H 3}$ using (a) method 1 and (b) method 2. The time axis corresponds to minutes after 1500 MDT.

The CP-2 radar scanned this storm during the entire rainfall event recorded by the rain gauge. However, the CHILL radar began its scans at about 1536 MDT, more than $15 \mathrm{~min}$ into the event. This "lost" time period for the CHILL radar was recovered from the earliest scan at 1536 MDT by taking $1200-m$ sections along the cell track that had already passed over the rain gauge. This process invoked the assumption that the cell structure did not change significantly over the 15 min time period. Time-height contours of maximum reflectivity and specific attenuation from the CP-2 radar over a $2 \mathrm{~km} \times 2 \mathrm{~km}$ rectangular "box" centered over the rain gauge location and extending in height from $0.5 \mathrm{~km}$ to near storm top were examined for the storm duration (1517-1605 MDT). It was verified that the vertical storm structure was nearly the same for the 15-min period prior to 1536 MDT.

\section{b. Method 2}

In the second method used for comparing radar and rain gauge measurements of $R$, the range gate directly above the rain gauge was used. The data point for the radar estimate of $R$ was again shifted by $200 \mathrm{~s}$, but this time in the opposite direction, that is, to an earlier time than the PPI scan time. For the CHILL data it was again necessary to extract all times prior to $1536 \mathrm{MDT}$ by taking data along the part of the track in the earliest PPI scan that already passed over the rain gauge location.

\section{c. Results}

Figure 4a shows the rain gauge measurements of $R$ together with $R_{\mathrm{KDP}}$ and $R_{A H 3}$ obtained by method 1 . These results indicate that $R_{\mathrm{KDP}}$ and $R_{A H 3}$ are in good agreement with the rain gauge measurements. Even the less sophisticated method-method 2-produced good results as seen in Fig. $4 \mathrm{~b}$. Figure 5 shows the rainfall rates obtained from the $R-Z$ relation of Eq. (3), where $Z_{H}$ is truncated at 50,55 , and $60 \mathrm{~dB} Z$. It is clear that the $55-\mathrm{dB} Z$ truncation produces the best $R-Z$ result for this case, and to our knowledge appears to be in use for the Denver WSR-88D. However, this cannot be generalized to all storms without significant error as the truncation point will depend on hail rate and maximum hail diameter. For example, Balakrishnan
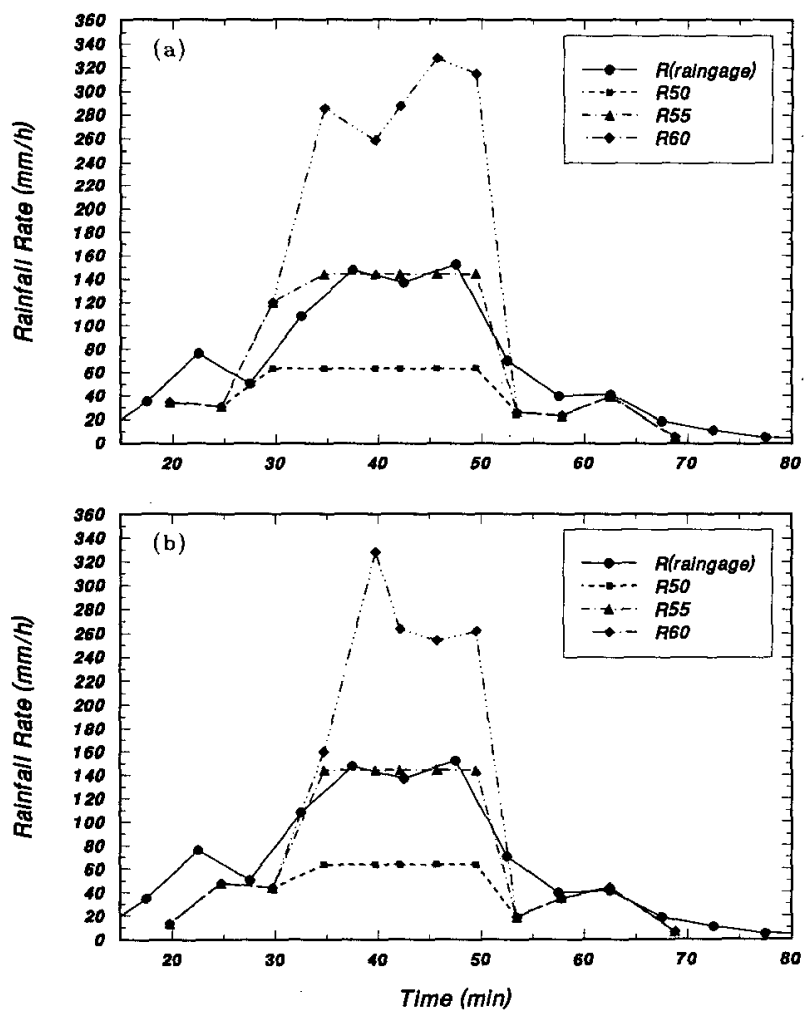

Fig. 5. Rainfall rates measured by the rain gauge and estimated from radar measurements of $Z_{H}$, which was truncated at 50-, 55-, and $60-\mathrm{dB} Z$ peak values, using (a) method 1 and (b) method 2 . The time axis corresponds to minutes after 1500 MDT. 
TABLE 1. Rainfall accumulation $(\Sigma)$ obtained from Figs. 4 and 5 and their difference relative to the rain gauge $(\Delta)$.

\begin{tabular}{|c|c|c|c|c|c|c|c|c|c|c|c|}
\hline & \multirow[b]{2}{*}{ Rain gauge } & \multicolumn{5}{|c|}{ Method 1} & \multicolumn{5}{|c|}{ Method 2} \\
\hline & & $K_{\mathrm{DP}}$ & $A_{H 3}$ & $Z_{H}(50)$ & $Z_{H}(55)$ & $Z_{H}(60)$ & $K_{\mathrm{DP}}$ & $A_{H 3}$ & $Z_{H}(50)$ & $Z_{H}(55)$ & $Z_{H}(60)$ \\
\hline$\Sigma(\mathrm{mm})$ & 73.3 & 79.7 & 77.5 & 38.6 & 69.3 & 117.5 & 70.2 & 72.4 & 37.6 & 63.5 & 96.5 \\
\hline$\Delta(\%)$ & 0 & 9 & 6 & -47 & -5 & 60 & -4 & -1 & -49 & -13 & 32 \\
\hline
\end{tabular}

and Zrnić (1990) provide model results for mixed precipitation composed of raindrops and wet, dry, or spongy hail using the Cheng and English (1983) hail size distribution model with minimum and maximum hail diameters of 3.75 and $60 \mathrm{~mm}$, respectively. Their results show that for a constant "spongy" hailfall rate of around $10 \mathrm{~mm} \mathrm{~h}^{-1}$, the $Z_{H}$ is constant at $55 \mathrm{dBZ}$ even when rain rate increases from zero to $50 \mathrm{~mm} \mathrm{~h}^{-1}$ (the upper rain-rate value varies from 30 to 130 $\mathrm{mm} \mathrm{h} \mathrm{h}^{-1}$ depending on dry or wet hail model).

An important parameter of a rain event is the rainfall accumulation. Table 1 presents the accumulation results from the various estimation methods presented in Figs. 4 and 5. It is seen that both $K_{\mathrm{DP}}$ and $A_{H 3}$ produce accumulation values within $10 \%$ of the rain gauge measurements. The $R-Z$ relation with $Z_{H}$ truncated at $55 \mathrm{dBZ}$ also produces good results, $-5 \%$ with method 1 and $-13 \%$ with method 2 . Truncating $Z_{H}$ at 50 or $60 \mathrm{dBZ}$ increases the relative errors dramatically, up to $-47 \%$ and $60 \%$ with method 1 and $-49 \%$ and $32 \%$ with method 2 , respectively.

\section{Conclusions}

This paper demonstrated the capability of $K_{\mathrm{DP}}$ for estimating rainfall rates in a severe storm with rainfall accompanied by hail. The radar estimates of $R$ were compared with measurements from a ground-based rain gauge. In addition to the $R-K_{\mathrm{DP}}$ relation, $R-A_{H 3}$ and $R-Z$ relations were also tested. Both $K_{\mathrm{DP}}$ and $A_{H 3}$ produced rainfall rates in good agreement with the rain gauge measurements. The rainfall accumulation estimates were within $10 \%$ of the rain gauge value. With the $R-Z$ relation, the best results were obtained when $Z_{H}$ was truncated at $55 \mathrm{dBZ}$. However, truncating $Z_{H}$ at 50 or $60 \mathrm{dBZ}$ produced poorer results. It is worth noting that $K_{\mathrm{DP}}$ and $A_{H 3}$ are independent of the radar system gain, unlike $Z_{H}$, and as a result will not be biased by such uncertainties, which can easily exceed $1 \mathrm{~dB}$. Furthermore, $K_{\mathrm{DP}}$ is sensitive to raindrops that are highly aligned with oblate shapes, and is not so sensitive to irregularly shaped or tumbling hailstones. These aspects of $K_{\mathrm{DP}}$ make it attractive for estimating $R$ in the presence of hail and can potentially serve as "ground truth" for evaluating rainfall accumulation algorithms based on $R-Z$ techniques, for example, the NEXRAD precipitation algorithms.
Acknowledgments. This research was supported by the National Science Foundation (NSF) Grant ATM9225116 and the Army Research Office Contract DAAL03-89-K-0158 at The Pennsylvania State University. During the course of this research Dr. K. Aydin was at CSU on sabbatical leave from Penn State. The CSU-CHILL radar is a national facility supported by the NSF Grant ATM-8919080. Dr. Li Liu was supported by the NSF Grant ATM-9014600. The CP-2 radar data were acquired as part of RAPS- 92 field program and were made available to the authors courtesy of Drs. Brandes and Vivekanandan of NCAR/Research Applications Division. The rain gauge data were supplied by Mr. N. Doeskin, Assistant State Climatologist at the Colorado Climate Center. The authors also acknowledge the assistance rendered by $\mathrm{Mr}$. $\mathrm{Pa}$ trick Kennedy of the CSU-CHILL radar facility.

\section{REFERENCES}

Atlas, D., and C. W. Ulbrich, 1977: Path- and area-integrated rainfall measurement by microwave attenuation in the $1-3 \mathrm{~cm}$ band. J. Appl. Meteor., 16, 1322-1331.

Aydin, K., and V. Giridhar, 1992: C-band dual-polarization radar observables in rain. J. Atmos. Oceanic Technol., 9, 383-390.

- T. A. Seliga, and V. Balaji, 1986: Remote sensing of hail with a dual linear polarization radar. J. Climate Appl. Meteor., 25, $1475-1484$.

Balakrishnan, N., and D. S. Zrnić, 1990: Estimation of rain and hail rates in mixed-phase precipitation. J. Atmos. Sci., 47, 565-583.

Battan, L. J., 1973: Radar Observations of the Atmosphere. University of Chicago Press, 84-113.

Bringi, V. N., T. A. Seliga, and K. Aydin, 1984: Hail detection using a differential reflectivity radar. Science, $225,1145-1147$.

- D. Brunkow, V. Chandrasekar, S. Rutledge, P. Kennedy, and A. Mudukotore, 1993: Polarimetric measurements in Colorado convective storms using the CSU-CHILL radar. Preprints, 26th Int. Conf. on Radar Meteorology, Norman, OK, Amer. Meteor. Soc., 519-521.

Chandrasekar, V., V. N. Bringi, N. Balaskrishnan, and D. S. Zrnić, 1990: Error structure of multiparameter radar and surface measurements of rainfall. Part III: Specific differential phase. $J$. Atmos. Oceanic Technol., 7, 621-629.

Cheng, L., and M. English, 1983: A relationship between hailstone concentration and size. J. Atmos. Sci., 40, 204-213.

Doviak, R. J., and D. S. Zrnić, 1993: Doppler Radar and Weather Observations. 2d ed. Academic Press, 254-255.

Hubbert, J., V. Chandrasekar, and V. N. Bringi, 1993: Processing and interpretation of coherent dual-polarized radar measurements. J. Atmos. Oceanic Technol., 10, 155-164.

Jameson, A. R., 1983: Microphysical interpretation of multiparameter radar measurements in rain. Part I: Interpretation of polarization measurements and estimation of raindrop shapes. J. Atmos. Sci., 40, 1792-1802. 
- 1991: A comparison of microwave techniques for measuring rainfall. J. Appl. Meteor., 30, 32-54.

- 1992: The effect of temperature on attenuation correction schemes in rain using polarization propagation differential phase shift. J. Appl. Meteor, 30, 1106-1118.

- and E. A. Mueller, 1985: Estimation of propagation differential phase shift from sequential orthogonal linear polarization radar measurements. J. Atmos. Oceanic Technol., 2, 133-137.

Kelsh, M., 1989: An evaluation of the NEXRAD hydrology sequence for different types of convective storms in northeastern Colorado. Preprints, 24th Conf. on Radar Meteorology, Tallahassee, FL, Amer. Meteor. Soc., 207-210.

Liu, L., V. N. Bringi, I. J. Caylor, and V. Chandrasekar, 1993: Intercomparison of multiparameter radar signatures from Florida storms. Preprints, 26th Int. Conf. on Radar Meteorology, Norman, OK, Amer. Meteor. Soc., 733-735.

,-- , V. Chandrasekar, E. A. Mueller, and A. Mudukotore,
1995: Statistical characteristics of the copolar correlation coefficient. J. Atmos. Oceanic Technol., 12, in press.

Marshall, J. S., and W. McK. Palmer, 1948: The distribution of raindrops with size. J. Meteor., 5, 165-166.

Sachidananda, M., and D. S. Zrnić, 1986: Differential propagation phase shift and rainfall rate estimation. Radio Sci., 21, 235-247.

$\longrightarrow$, and - 1987: Rain rate estimated from differential polarization measurements. J. Atmos. Oceanic Technol., 4, 588-598.

Seliga, T. A., and V. N. Bringi, 1976: Potential use of radar differential reflectivity measurements at orthogonal polarizations for measuring precipitation. J. Appl. Meteor., 15, 69-76.

$\longrightarrow$, and - 1978: Differential reflectivity and differential phase shift: Applications in radar meteorology. Radio Sci., 13, 271275.

Ulbrich, C. W., 1983: Natural variations in the analytical form of the raindrop size distribution. J. Climate Appl. Meteor., 22, $1764-1775$. 